\title{
AMARRANDO AS PRÓPRIAS BOTAS DO DESENVOLVIMENTO: A NOVA ECONOMIA GLOBAL E A RELEVÂNCIA DE UM DESENHO JURÍDICO-INSTITUCIONAL NACIONALMENTE ADEQUADO
}

Mario Gomes Schapiro

\section{RESENHA}

RODRIK, Dani. The New Global Economy and DeVeloping COUNTRIES: MAKING OPENNESS WORK. WASHINGTON: OVERSEAS DeVelopment COUnCiL, 1999.

1

ratando-se de um livro heterodoxo, como é o The New Global Economy and Developing Countries - making openness work, de Dani Rodrik, talvez uma maneira aceitável de iniciar uma resenha seja justamente apresentando o argumento de outros autores. Não por nenhum lampejo de erudição estéril, mas apenas para aproximar o debate proposto por Rodrik de algumas outras abordagens com as quais seu argumento é convergente. Por estes meios, acredita-se que, se, ao menos, a resenha não se tornar consistente, o autor, que não é economista, estará protegido, já que as suas referências iniciais serão justamente trabalhos de dois professores de Direito, com os quais Rodrik tem apresentado um fértil diálogo: Charles Sabel e Roberto Mangabeira Unger.

Pois bem, em uma conferência, ocorrida em 2004, sobre a ética protestante e o espírito do capitalismo, o historiador econômico e professor da Columbia Law School, Charles Sabel, apresentou um instigante paper a respeito das estratégias bem sucedidas de crescimento econômico. A tese do autor é de que os países detentores de trajetórias exitosas de 
desenvolvimento são justamente aqueles que basearam as suas apostas em um desenho institucional nacionalmente adequado. A ideia força do artigo é bem traduzida pela metáfora de seu título, Bootstrapping Development, cuja aproximada tradução seria: desenvolvendo-se por conta própria ou amarrando as próprias botas do desenvolvimento ${ }^{1}$.

$\mathrm{O}$ argumento que Sabel desenvolve neste trabalho é uma fundamentada provocação às proposições que se forjaram no mainstream internacional, desde meados da década de 1990, acerca das corretas estratégias de desenvolvimento econômico e que são, via de regra, sugeridas como medidas corretas a serem adotadas pelos países retardatários. Desde que foi forjado um novo consenso teóricoprático entre policy makers, pesquisadores e representantes de órgãos multilaterais de crédito, como o Banco Mundial e o Fundo Monetário Internacional ${ }^{2}$, as propostas de um modelo nacional de desenvolvimento foram encurraladas e mantidas sob uma intensa artilharia de críticas e condenações.

De fato, a partir dos anos 1990, as estratégias de organização econômica centradas no protagonismo do Estado e na defesa dos interesses nacionais caíram em desuso no rol de políticas consideradas corretas, muito embora tenham alicerçado o crescimento de boa parte dos países da periferia e da semiperiferia, nas décadas de 1960 e 1970. De 1990 em diante, as recomendações para a abertura da economia assumiram o papel de timoneiro seguro para transição dos países até patamares ótimos de desenvolvimento. Bastava aos países mais empobrecidos que eliminassem as barreiras tarifarias e não tarifárias, controlassem o déficit público, diminuíssem o tamanho do setor produtivo estatal, por meio de privatizações, e os maus resultados verificados na década de 1980, supostamente atribuídos ao fracasso das políticas de substituição de importações, seriam plenamente equacionados. Em síntese, tratava-se da necessidade de se realizar reformas orientadas para o mercado, que seriam capazes de garantir a atração de investimentos diretos externos IDE, de aumentar o fluxo de exportações e assim prover melhores resultados para o futuro das comunidades nacionais.

A base destas reformas contava com um certo padrão institucional. É dizer, as recomendações articuladas pelo novo consenso, estabelecido por acadêmicos e formuladores de políticas públicas, no cenário internacional, seriam respaldadas por reformas institucionais no âmbito nacional, que dariam suporte a uma economia aberta e de fluxo comercial irrestrito. Tais instituições seguiam um padrão, uma fórmula de tipo one size fits all, que era difundida para diversos e distintos países, como os da América Latina, da Europa Oriental, Ásia e África.

Esta fórmula geral cingia-se a construção de novas alternativas institucionais, que resumidamente significavam a substituição dos mecanismos jurídicos de intervenção do Estado na economia, até então prevalecentes, por um padrão de organização econômica identificado pelo 
arquétipo do Rule of Law. No caso, esta expressão não é utilizada no mesmo sentido jurídico de Estado de Direito ${ }^{3}$, mas, meramente, em alusão a "regras do jogo". Trata-se, na verdade, da descrição de um padrão de atuação do Estado e do Direito no cenário econômico, segundo o qual, as instituições jurídicas, como o contrato ou a propriedade, se comprometem com a definição das macrobalizas, ou das regras gerais, do funcionamento dos mercados.

Trata-se, pois, de se reformar o ambiente institucional com vistas a suprimir os instrumentos de ação do Estado e substituí-los por uma espécie de standard regulatório, vinculado ao programa mais amplo do Consenso de Washington, para o qual, o papel do Estado e do Direito é garantir a segurança jurídica, ou as "regras do jogo" para o ambiente de negócios. Os próceres deste consenso julgavam que, uma vez conformado um espaço econômico seguro, as economias nacionais estariam corretamente conformadas e preparadas para sustentar um ciclo ascendente de desenvolvimento econômico.

É justamente este o ponto da discórdia de Charles Sabel. Para o autor, o equívoco das análises do mainstream estaria em assumir o padrão institucional do Rule of Law como se fosse uma espécie de dotação natural de fatores, uma fórmula correta e única para a organização dos processos econômicos. Em outros termos, haveria nestas análises e proposições reformistas de Washington, aquilo que Roberto Mangabeira Unger4 - um dos interlocutores de Sabel e de Rodrik designa como um fetichismo institucional: uma crença de que haveria um leque limitado de alternativas institucionais adequadas e portadoras da capacidade de promover mercados eficientes, de tal modo que, uma vez de posse deste arcabouço, os países assumiriam rigorosamente uma rota proeminente de crescimento.

$\mathrm{Na}$ realidade, argumenta Sabel, se é inegável que o arranjo institucional é uma variável dos processos de desenvolvimento, é absolutamente controversa a noção de que há um único padrão de organização econômica adequada transplantável para os mais distintos países. A rigor, o sucesso ou insucesso dos países está associado à sua capacidade de desenhar um marco institucional articulado e adequado a cada contexto particular. Desta maneira, os arranjos institucionais seriam, a um só tempo, capazes de incentivar as atividades econômicas nacionais e seriam produto do ambiente histórico, social e cultural. No limite, a imagem de se amarrar as próprias botas, para então poder caminhar, reúne a ideia de que a organização do espaço econômico responde às vicissitudes nacionalmente construídas e, por tal razão, as instituições pressupostas são localmente customizadas.

Para ilustrar a sua tese, Sabel argumenta que deve se passar no âmbito das instituições conformadoras do mercado o mesmo processo de aprendizagem e adaptação que se passou na técnica de produção industrial de automóveis. Lembra o autor que, a criação do sistema de produção just in time (ou padrão toyotista), no Japão, foi um típico caso de adequação empresarial à realidade 
nacional. Carentes dos mesmos patamares de acumulação de capital para inversão de que dispunha a americana Ford Motors, os empresários japoneses não podiam apostar numa linha de produção de tipo fordista, que implicava um elevadíssimo investimento em estoques de peças, para sustentar o padrão de produção em série. Esta dificuldade inicial foi contornada com um novo padrão de organização industrial, no qual a oferta de peças para a montagem dos automóveis era simultânea (just in time), o que evitava uma aplicação exagerada de capitais em peças de estoque. Com esta adaptação organizacional, não só o Japão pode constituir fábricas nacionais de automóveis, como suas fábricas fecharão o ano de 2006 vendendo mais automóveis que a própria Ford no mercado americano. A moral desta história é clara: os países devem ter capacidade de aprendizagem e manufaturarem instituições adequadas ao seu processo econômico, para assim galgarem posições positivas na corrida internacional.

Pois bem, esta história de chão de fábrica e o resumo do argumento de Sabel apresentam-se como uma boa referência para se analisar um livro de um de seus mais relevantes interlocutores acadêmicos - o provocador e economista heterodoxo, Dani Rodrik. Em seu livro de 1999, intitulado The New Global Economy and Developing Coutries - making openness work, o professor de Harvard, vai justamente dialogar com os pretensos cânones atuais da economia do desenvolvimento. Assumindo a premissa normativa do mainstream de que as economias atuais devem funcionar de maneira aberta,
Rodrik discute o quanto de falacioso há na causalidade apontada pelo senso comum, segundo o qual, uma vez garantidas as instituições reguladoras da abertura econômica, tudo o mais e de melhor viria a reboque. Ao inverter o sinal deste vetor, Rodrik, assim como o seu parceiro intelectual Charles Sabel, acentua o papel das estratégias singularmente nacionais e consequentemente dos mecanismos nacional-específicos de organização econômica. Em última análise, mostra Rodrik, não é a abertura comercial e a aderência ao padrão regulatório internacional que garante crescimento. É justamente o oposto: a capacidade de se despertar crescimento interno leva as economias nacionais a um patamar de desenvolvimento, cuja consequência é um percurso de sucesso na economia global.

A partir destes elementos, a proposta desta resenha é apresentar o argumento do livro de Dani Rodrik e, a partir disso, buscar alguma reflexão sobre a trajetória recente do desenho institucional brasileiro. Para tanto, este trabalho está dividido em outras duas sessões, a próxima apresentará a tese do livro de Rodrik e, ainda, fará algumas referências sobre o padrão institucional do Brasil, e a última sessão procurará trazer uma conclusão.

\section{A abertura eConômica e} A NECESSIDADE DE INSTITUIÇÕES NACIONALMENTE ADEQUADAS PARA IMPULSIONAR O DESENVOLVIMENTO

Não seria equivocado resenhar o livro de Dani Rodrik, The New Global Economy and 
Developing Coutries - making openness work, buscando-se com isso responder à seguinte questão: diante de uma economia aberta, por que países, com semelhantes condições de largada alcançaram posições desiguais no pódio da corrida do desenvolvimento, ocorrida ao longo da década de 1990?

Embora o autor não tenha formulado esta questão, ao menos não desta maneira, o argumento do livro soa como uma precisa e desconcertante resposta. Precisa porque se baseia em estudos comparados de mais 42 países (estudos cross countries) e leva em conta diversos indicadores, como nível de produtividade, renda e crescimento anual do PIB. Desconsertante porque mostra que os países bem-sucedidos nestes indicadores não foram aqueles que seguiram as prescrições recomendadas pela vertente hegemônica de pensamento social sobre desenvolvimento econômico. O livro enfim é um justo reconhecimento aos países rebeldes.

Até então, perdurava, sem muita oposição teórica, a noção de que a abertura da economia e a integração dos mercados eram, não só inevitáveis, como desejáveis. As apostas de desenvolvimento autárqui$\mathrm{co}$, isto é baseadas em estratégias nacionais e fechadas à competição internacional, eram identificadas como ultrapassadas e inadequadas. De acordo com as análises do (daquilo que Rodrik identifica como) mainstream, os modelos de crescimento sustentados por políticas de proteção de mercados e de substituição das importações, como registrado no Brasil, entre 1950 e 1990, foram mal sucedidos, já que impediam o fluxo de comércio e assim não colaboravam para garantir uma razoável captação de recursos externos, seja via investimento direto externo, seja via exportações.

$\mathrm{O}$ argumento ortodoxo, aliás, parece até razoável, já que se tratam de países em desenvolvimento e como tais, acometidos da falta de recursos para investimentos. A superação desta intrincada situação passaria, então, pela busca incessante de divisas estrangeiras, para o que seria necessária uma organização da economia voltada predominantemente para fora (outward orientation). De mais a mais, diriam os partidários do consenso forjado em Washington, os países da periferia, sobretudo, os latino-americanos ao apostarem em estratégias endógenas de desenvolvimento, como as políticas substitutivas de importações, comprometeram a produtividade de suas economias, que por serem fechadas não acompanhavam o ritmo da competitividade internacional.

Como se sabe, o fundamento último desta avaliação repousa sobre a noção ricardiana das vantagens comparativas, o que significa dizer que o comércio internacional deteria como predicado a potencialidade de articular ganhos para todos os players ${ }^{5}$. A manutenção dos preços relativos corretos, isto é, isentos de intervenções regulatórias artificiais, permitiria que os países retardatários se especializassem nos ramos nos quais são naturalmente competitivos, o que lhes facultaria a capacidade de atração de investimentos e de geração de recursos via trocas internacionais. 
De posse das certezas deste diagnóstico conceitual e diante da crise econômica que se arrastava desde meados dos anos 1980, em diversos países em desenvolvimento, principalmente, naqueles do continente americano, os diversos governos nacionais não hesitaram em atender às recomendações do mainstream internacional. $\mathrm{O}$ rol de medidas liberalizantes foi ampla e difusamente aplicado, por meio de reformas institucionais extensas. As empresas públicas foram privatizadas, a política fiscal e orçamentária foi rigidamente disciplinada e, mais que tudo, as barreiras tarifárias e não tarifárias foram cortadas.
A esse respeito, e só à título de exemplo, a tabela abaixo apresenta o ritmo de abertura econômica ocorrida no Brasil. Em 1991, o Ministério da Fazenda, por meio da Portaria 58, de 31 de janeiro de 1991, estabeleceu uma reforma tarifária, indicando uma ampla e substancial redução das tarifas de importação, o que ocorreria até o ano de 1994. Esta Portaria, por sua vez, veio a ser substituída pela Portaria 131/92, que reviu o prazo inicialmente estipulado, estabelecendo, então, que a redução tarifária ocorreria até 1993 e 1994 - o que de fato veio a ocorrer ${ }^{6}$. Pode-se perceber que no prazo de dois anos, a média de tarifas de importação caiu pela metade.

\section{Tabela oi. Evolução das Tarifas de IMPORTação}

\begin{tabular}{lllll} 
DATAS & MÉDIA & MEDIANA & INTERVALO & DESVIO PADRÃO \\
\hline 1990 & $32,2 \%$ & 30 & $0-105$ & 19,6 \\
\hline FEV/1991 & $25,3 \%$ & 25 & $0-85$ & 17,4 \\
\hline JAN/1992 & $21,2 \%$ & 20 & $0-65$ & 14,2 \\
\hline OUT/1992 & $16,5 \%$ & 20 & $0-55$ & 10,7 \\
\hline JUL/1993 & $14,9 \%$ & 20 & $0-40$ & 8,2 \\
\hline DEZ/1994 & $11,2 \%$ & 9,8 & $0-24$ & 5,9 \\
\hline DEZ1995 & $13,9 \%$ & 12,8 & $0-55$ & 9,5 \\
\hline
\end{tabular}

Elaborada por David Kupfer ${ }^{7}$

Mesmo assim, e adotando diversas outras medidas do pacote de "boas práticas”, como, por exemplo, a privatização de mais de 37 grupos empresariais estatais, a retração da política industrial, como meio de evitar os rent-seekers, a constituição de marcos regulatórios estáveis para a atração de capital externo, a implementação de uma reforma gerencial para reduzir os custos da máquina pública, entre outros, o Brasil, ao final da década de 1990, passava por uma curiosa situação: em comparação com países como a Coreia do Sul, crescera 
menos naquele período em que as "boas práticas” de desenvolvimento foram aplicadas do que no contexto anterior, em que vigeu o modelo endógeno de desenvolvimento. A tabela abaixo apresenta estes dados.

\section{TABEla 02. DESEMPENHO ECONÔMICO COMPARAdo - BRASIL E COREIA do SUL}

\begin{tabular}{llll}
\hline TAXA MÉDIA ANUAL DO PERÍODO 1950-1980 & $6,5 \%$ & TAXA MÉDIA ANUAL DO PERÍODO 1950-1979 & $6,5 \%$ \\
\hline TAXA MÉDIA ANUAL DO PERÍODO 1981-2000 & $1,6 \%$ & TAXA MÉDIA ANUAL DO PERÍOD0 1980-2000 & $5,4 \%$ \\
\hline
\end{tabular}

Elaborado por Luciano Coutinho ${ }^{8}$, com base em fontes nacionais, BIRD e FMI

Aliás, não deixa ainda de ser interessante notar que o volume de investimentos no setor produtivo brasileiro decresceu desde a década de 1970, período no qual o país apostou nas "práticas ruins". O período 1972-1980 foi o que registrou maior volume de investimentos, ao passo que o período 1988-1993 respondeu pelas menores taxas de inversões. Somente no biênio 1995-1997 é que a taxa de investimentos na indústria voltou a ser a mesma que a verificada entre 1981 e 1988, mas ainda inferior à da década de 1970, como indica a tabela abaixo.

\section{TABela o3. INVESTIMENTO INDUSTRIAL COMO PERCENTAGEM DO PIB} (preços constantes de 1980)

\begin{tabular}{ll} 
PERÍODO & \% DO PIB \\
\hline $1972-1980$ & 4,5 \\
\hline $1981-1988$ & 3,2 \\
\hline $1988-1993$ & 2,2 \\
\hline $1995-1997$ & 3,2 \\
\hline
\end{tabular}

São situações como estas, dentre tantas outras, que RODRIK procura explicar em seu livro. Para tanto, o autor inverte a causalidade de fatores sustentada pela abordagem ortodoxa. A rigor, não seria a abertura econômica e a articulação de uma internacionalização da economia que per se responderiam pelo êxito ou fracasso de determinadas nações. Na realidade, as economias de países emergentes que 
obtiveram ganhos no comércio internacional foram aquelas que já se encontravam em um patamar adequado de desenvolvimento nacional. Em última análise, não seria a aposta na mundialização o fator determinante do desenvolvimento, mas a definição nacional de uma trajetória de desenvolvimento é que provoca uma corrida para a conquista dos mercados internacionais.

A constatação do estudo de Rodrik é que o decisivo para o crescimento dos países investigados foi a definição e a implementação de um desenho de instituições que desse conta de duas atribuições:

i. a ampliação no nível de investimento privado e, ii. o gerenciamento dos conflitos distributivos.

Com relação ao impulso do investimento privado, é preciso ter em conta que esta é uma não questão para os postulados da economia neoclássica, que sustenta, em última instância, as análises e recomendações do mainstream. Para economia marginalista, assentada no individualismo metodológico, o mecanismo de mercado é assumido como um leilão, de tal modo que os preços são o meio de comunicação entre os ofertantes e os demandantes. Supostamente, todas as demandas individuais serão sempre atendidas, já que acarretarão uma remuneração justa para o produtor, que então se dedicará à produção destes bens. Por extensão, ausente a noção de falha de mercado, se passaria o mesmo com bens de fruição coletiva, já que a busca do interesse pessoal leva toda a comunidade a uma situação de prodigalidade.

Concretamente, isto significa que, por meio do mecanismo de mercado, a economia como um todo tende a um funcionamento adequado. No entanto, esta não questão se torna um efetivo problema para aquelas economias que teimam em escapar da tipologia científica. Os países em desenvolvimento apresentam falhas histórico-estruturais em suas economias e, como lembra Rodrik, nestes países verificam-se situações em que a rentabilidade de um investimento privado muitas vezes não corresponde à sua demanda. Noutros termos, a carência de recursos disponíveis nestes países e a ausência de empreendedores com larga capacidade de investimento faz com que inversões necessárias deixem de ser realizadas, já que se mostram desinteressantes para o investidor. Em situações como esta, os preços de mercado não são bons comunicadores e a sua defesa intransigente só garante a inércia destas economias.

Não por outra razão que uma trajetória de crescimento deve contar com um arranjo institucional capaz de articular ganhos econômicos, ainda que artificialmente, para aqueles investimentos relevantes para o país. Os países em desenvolvimento bem sucedidos, como os tigres asiáticos, se esquivaram de manter os preços certos (definidos somente pelo jogo do mercado) e apostaram na intervenção do Estado para garantir retornos econômicos que não seriam providos pela lei da oferta e da procura. 
Em suma, o crescimento econômico ancora-se nas taxas de investimento nacional, que, em algumas situações, se não estimuladas, não ocorrem por conta e risco da classe capitalista. O gargalo do crescimento, portanto, está em definir mecanismos regulatórios e políticas que sejam capazes de alavancar a capacidade de investimento nacional.

Estes argumentos tornam-se bastante palpáveis com a comparação exemplificativa que Rodrik faz entre dois paradigmas: o grupo dos rebeldes, Coreia do Sul, Singapura e Taiwan, com o bem comportado Hong Kong. O grupo dos rebeldes contava com baixas taxas de investimento e a superação deste obstáculo contou fortemente com o Estado, que orientou a alocação dos recursos, via créditos, como na Coreia do Sul, ou via incentivos tributários, como em Taiwan, e assim articulou retornos econômicos que incentivaram o aumento do montante de investimentos. Por sua vez, Hong Kong portou-se bem e deixou que o mercado funcionasse pelas suas próprias pernas. Isso desconfirmaria a tese de Rodrik? De modo algum diz o autor: Hong Kong, à distinção dos demais tigres, já contava com um patamar de investimentos privados nacionais elevados, de tal modo que a participação alavancadora do Estado era desnecessária, diferentemente do que se passava com os outros países da região. Nos termos de Rodrik:

For countries with a wellestablished entrepreneurial class and an investment rate already at or above, say, 25 percent, this presumption may well be right. But for poorer countries with low levels of private investment and nondiversified production structures, more is likely to be needed. The lesson from East Asia is clear: the three East Asia 'dragons' with low investments rates in the early 1960 s - South Korea, Taiwan and Singapore - would not have been nearly as successful had their governments not given capital accumulation a big push by subsidizing, cajoling, and otherwise stimulating private investors ${ }^{10}$.

Apesar de que a citação de Rodrik faz explícita referência ao período inicial de desenvolvimento destes países, é conveniente lembrar que o padrão de engajamento do Estado se manteve ativo nestes países mesmo nos anos 1990. Até o insuspeito Banco Mundial, em seu relatório de 1997, The East Asian Miracle, reconheceu as virtudes da configuração institucional de países como a Coreia, que até os dias atuais define planos quinquenais de desenvolvimento.

Em reforço a este ponto, alguns estudos recentes sobre os países em desenvolvimento, igualmente sobre o leste asiático, têm chamado a atenção para o fato de que nestas economias tem sido relevante o papel do Estado como parceiro do desenvolvimento. Em seu comentado livro sobre a Coreia do Sul, Alice Amsden ${ }^{11}$, por exemplo, argumenta que a hipótese schumpeteriana, de que o desenvolvimento seria gerado a 
partir das inovações tecnológicas desenvolvidas pelos empresários inovadores, não é valida para os países da periferia econômica. Isto porque, o que qualifica estes países é a baixa capacidade empresarial de investir em progresso técnico, o que demanda um maior envolvimento do Estado como indutor do desenvolvimento. Segundo a autora, a tarefa para os Estados de países subdesenvolvidos extrapola a conformação do mercado (market conforming paradigm). Na realidade, a evidência histórica coreana permite concluir que o desenvolvimento depende de uma atuação estatal verdadeiramente geradora de mercado (market augmenting paradigm). Nas palavras de Amsden: "Growth in late-industrializing countries depends on government intervention to augment supply and demand."12

Da mesma forma, Ha Joon Chang ${ }^{13}$, ao reconstruir o conceito de um Estado envolvido no desenvolvimento econômico - o Developmental State -, faz referência à distinção existente nos processos de acumulação das economias periféricas em relação às centrais, o que reclama, para o autor, uma distinta participação do Estado nestes processos econômicos. Tais distinções partem do fato de que os países em desenvolvimento padecem de falhas econômicas estruturais, tais como: (i) a falta de volume de capital necessário para constituir as escalas necessárias para competitividade internacional; (ii) a defasagem entre o nível de acumulação interna e o padrão de acumulação das nações desenvolvidas; (iii) a ausência de agentes capitalistas com capacidade empreendedora e (iv) presença de um acentuado gap tecnológico. O resultado obtido é o de uma situação econômica entravada, em que a atuação privada não é suficiente para dinamizar a economia. A seguinte passagem de Chang resume o seu argumento:

The developmental process require more than what I have just decribed-namely, coordinating a simultaneous move from a lowequilibrium to a high equilibrium state. This is because economic development, as Albert Hirschman said a long time ago in his critique of Big Push models, "depends not so much on finding optimal combinations for given resources and factors of production as on calling forth and enlisting for development purposes resources and abilities that are hidden, scattered, or badly utilised. ${ }^{14}$

A outra missão institucional assinalada por Rodrik é relativa ao gerenciamento dos conflitos distributivos. De acordo com o autor, paralelamente às estratégias de alavancagem do investimento privado, a capacidade de administração do conflito distributivo é uma tarefa de relevância. A suposição que respalda esta abordagem é a de que quanto pior o estado da arte da distribuição da renda, menos estáveis se tornam os países e, assim, mais propensos a medidas econômicas que podem gerar um desequilíbrio macroeconômico. Um desarranjo desta natureza, por sua vez, é deletério para o ambiente de negócios, e 
acaba impactando a disponibilidade de investimentos privados.

Portanto, o desenho institucional deve ter como tarefa a construção de um espaço de democracia materialmente estável - única forma de se evitar pressões e desequilíbrios contraproducentes para o ambiente de investimentos.

\section{ConClusão}

Embora se trate de uma resenha, talvez seja interessante afirmar alguns pontos como uma conclusão. O primeiro deles é demonstrar a convergência entre as análises de Sabel e de Rodrik, quanto à desconfiança das fórmulas de tipo one size fits all. Fórmulas estas que se baseiam, no mais das vezes, na defesa de mercados seguros e abertos como meios de alcançar o desenvolvimento. Contra esse recomendacionismo, Sabel argumenta em favor da capacidade de aprendizado institucional e da customização nacional dos aparatos organizativos.

Essa defesa de Sabel é apoiada e intensificada pelos argumentos de Rodrik, que, basicamente sustenta dois pontos: (i) a vinculação entre crescimento e estratégias nacionais de investimento e (ii) a organização de mecanismos de estabilização social que previnam as turbulências macroeconômicas. O contato entre os autores está no fato de que tanto a alavancagem de investimentos privados, como a administração dos conflitos, demanda estratégias nacional-específicas de organização econômica e não se resolve com fórmulas institucionais fetichizadas.

Os países bem sucedidos foram justamente aqueles que reconheceram as suas fraquezas e foram capazes de delinear um ambiente propício ao investimento privado - do que resultou um crescimento sustentado e um bom desempenho na economia global. Por assim dizer, aqueles que amarraram as próprias botas do desenvolvimento, ao invés de permanecer na condição de expectador das tendências internacionais, deram passos mais largos e mais consistentes. É o caso da Coreia do Sul, de Taiwan e de Singapura, mas não é o caso do Brasil e de boa parte da América Latina.
1 Vide SABEL, Charles. Bootstrapping Development: rethinking the role of public intervention in promoting grouth, paper apresentado na conferência Ética Protestante e o Espírito do Capitalismo, na Universidade de Cornell, mimeo, 2004.
2 A referência é ao que John Williamson denominou por Consenso de Washington. Um conjunto de 10 medidas acordadas pelos credores internacionais e pelos formuladores de políticas públicas de entidades multilaterais, como o BIRD e o FMI, e que deveriam ser 
empregadas pelos países periféricos, sobretudo os latinos, como meio de solucionar a crise fiscal e econômica de seus Estados. As medidas eram: disciplina fiscal; reorientação de despesas orçamentárias; reforma tributária; liberalização financeira; liberalização comercial; atração de investimentos diretos estrangeiros; privatização; desregulação econômica; fortalecimento dos direitos de propriedade e viabilização de taxas de retorno econômicas competitivas. Para mais detalhes, vide WILLIAMSON, John. What Washington Means by Policy Reform, in WILLIAMSON, John. How Much Has Happened?, Washington DC, Institute for International Economics, 1990, pp - 7-20.

3 Na tradição da teoria do direito e da teoria do Estado, a expressão Rule of Law é muitas vezes empregada para traduzir o conceito de Estado de Direito, ou seja, uma específica forma de organização jurídica do poder político, na qual o soberano está submetido à legalidade e deve respeitar direitos e garantias individuais. Trata-se, portanto, de um conceito mais abrangente do que o utilizado pelo Banco Mundial, por exemplo. Para uma leitura do Rule of Law como "regras do jogo", vide TRUBEK, David. The Rule of Law in Development Assistance: past, present and Future, paper, mimeo, 2003, disponível em http: / / dev.law.wisc.edu / / facstaff/trubek/ruleoflaw. htm, acesso em 16/10/2006.

4 Vide MANGABEIRA UNGER, Roberto. $O$ Direito e o Futuro da Democracia, (Trad. Caio Farah Rodriguez e Márcio Grandchamp) São Paulo, Boitempo, 2004, pp - 18-21.

5 De acordo com David Ricardo, cada país deteria vantagens em um determinado ramo de atividade. Diante disso, o caminho do sucesso passaria prioritariamente pelo reconhecimento e pela concentração de esforços nestes nichos. O resultado seria um ganho econômico equalizado para todos os países, já que naturalmente, sem qualquer intervenção artificial, cada nação produziria aqueles bens que lhe são mais pertinentes. Enfim, cada mercado nacional se especializaria naquilo que é o seu destino natural, já que a economia resulta da espontaneidade das forças privadas. Vide RICARDO, David. Princípios de Economía Política y Tributación, Trad. Juan Broc, Nelly Wolff e Julio Estrafa, $1^{\text {a }}$ ed. Quinta Reimpressão, México, D.F, Fondo de Cultura, 1994.

6 Cf. SUZIGAN, Wilson \& VILLELA, Annibal, Industrial Policy in Brazil, Campinas, Unicamp, 1997. pp 81-102

7 KUPFER, David. Trajetórias de Reestruturação da Industria Brasileira após a Abertura e a Estabilização, mimeo, Tese de Doutorado apresentada ao Instituto de Economia da UFRJ, 1998, disponível no site www.ufrj.br/ie

8 Vide COUTINHO, Luciano. Coréia do Sul e Brasil - paralelos, sucessos e desastres, in FIORI, José Luís (org) Estados e Moedas no Desenvolvimento das Nações, Petrópolis, Vozes, 1999, pp - 351-378.

9 KUPFER, David. A Indústria Brasileira após a Abertura, in CASTRO, Ana Célia et al. (orgs) Brasil em Desenvolvimento 1 - economia, tecnologia e competitividade, Rio de Janeiro, Civilização Brasileira, 2005, pp 202-231.

10 RODRIK, Dani. The New Global Economy and Developing Countries - making openness work, Washington DC, Overseas Development Council, 1999, p. 63.

11 Ver AMSDEN, Alice. Asia's Next Giant - South Korea and Late Industrialization. New York, Oxford University Press, 1989, pp - 139-155.

12 Cf. AMSDEN, Alice. Asia's Next Giant... op. cit. pp - 139-155.

13 CHANG, Ha-Joon. The Economic Theory of the Developmental State in WOO-CUMINGS, Meredith. The Developmental State. Cornell, Cornell University Press, 1999, pp - 182-199.

14 CHANG, Ha-Joon. The Economic Theory of the Developmental State... op.cit. pp - 182-199.

\section{Mario Gomes Schapiro}

Mestre e Doutorando em Direito Econômico PELA Faculdade DE DIREITO DA USP E PESQUISADOR DA FGV-EDESP 